\title{
COMUNICAÇÃO CIENTÍFICA PARA O PÚBLICO LEIGO: BREVE HISTÓRICO
}

\section{LA COMUNICACIÓN CIENTÍFICA PARA EL PÚBLICO NO CIENTÍFICO: HISTORIA BREVE}

\author{
Suzana P. M. Mueller - mueller@unb.br \\ Doutora em Ciência da Informação \\ Professora Titular do Programa de Pós-Graduação em Ciência da Informação, \\ Universidade de Brasília, UnB \\ Rita de Cássia do Vale Caribé - rita.caribe@gmail.com \\ Doutoranda do Programa de Pós-Graduação em Ciência da Informação, \\ Universidade de Brasília, UnB
}

\begin{abstract}
Resumo
Relato de fatos marcantes da história e da evolução da divulgação científica para leigos, que ocorreram na Europa entre os séculos $\mathrm{XV}$ e $\mathrm{XX}$, com breve referência a iniciativas nos Estados Unidos da América em épocas mais recentes. Os dados foram buscados em estudos publicados sobre o assunto e o escopo do texto privilegia acontecimentos até a introdução das novas tecnologias de informação e de comunicação, aos quais faz apenas breve menção. A ordem de exposição é cronológica, século por século, com a exceção de três temas - jornalismo científico, livros infantis e museus - que são tratados em seções específicas. A narrativa tem início no século $\mathrm{XV}$, destacando as primeiras iniciativas, que ocorreram paralelamente ao desenvolvimento da ciência e da imprensa. A partir daí, os principais acontecimentos de cada século são comentados: as novas academias de ciência que se espalharam pelo continente europeu e cujas atas dão origem aos primeiros periódicos científicos (século XVI); o livro como instrumento de divulgação científica (séculos XVII e XVIII); as conferências científicas como forma de divulgação do conhecimento científico dirigida à sociedade (século XVIII); a consolidação das disciplinas e da especialização, e, paralelamente, dos periódicos científicos separadamente dos veículos de divulgação científica.
\end{abstract}

\section{Palavras-chave}

Inf. Inf., Londrina, v. 15, n. esp, p. 13 - 30, 2010 
Comunicação da ciência. Comunicação científica. Divulgação científica. Divulgação científica - evolução histórica. História da ciência.

\section{INTRODUÇÃO}

A divulgação do conhecimento científico para o público leigo teve origem com a própria ciência moderna, na Europa do século XV. O acesso ao conhecimento científico pela sociedade em geral, hoje, um fato considerado desejável e corriqueiro nos países democráticos, teve um início marcado por repressão e preconceito, mas foi, aos poucos, conquistando espaço e reconhecimento. Neste texto, alguns dos fatos mais marcantes de sua história, que ocorreram, na Europa, entre os séculos XV e os dias atuais, são relatados. Há também referências breves a algumas iniciativas nos Estados Unidos da América (EUA) em épocas mais recentes. Os dados foram buscados em estudos publicados, e o escopo do texto privilegia os acontecimentos até a introdução das novas tecnologias de informação e de comunicação, aos quais faz apenas breve menção. A ordem de exposição é cronológica, século por século, com a exceção de três temas - jornalismo científico, livros infantis e museus - que são tratados em seções separadas.

\section{ORIGENS DA COMUNICAÇÃO DA CIÊNCIA MODERNA À SOCIEDADE ATUAL}

Nas últimas décadas do século XV, com o avanço da imprensa de tipos móveis de Gutenberg, iniciou-se transformação na história da transmissão de saberes (TOMÁS, 2005). O desenvolvimento da ciência ocorreu de forma concomitante com a invenção da imprensa, pois havia troca de documentos (cartas, monografias e livros) preferencialmente em latim, língua utilizada na Europa de então pelas pessoas cultas. À época, a troca de cartas e de outros documentos era a forma padrão de comunicação entre os indivíduos, em âmbito local e nacional (BURKETT, 1990; CALVO HERNANDO, 2006; TOMÁS, 2005; ZIMAN, 1981).

Para Calvo Hernando (2006), grandes homens da história naquele período já haviam percebido a importância da difusão do conhecimento e cita Leonardo da Vinci (1452-1519) como um divulgador, tendo em vista uma de suas afirmativas de que o dever do homem da ciência é a comunicação. Gerolamo Cardano (15011576), um quase contemporâneo de da Vinci, é também visto como precursor da divulgação científica por ter escrito, aproximadamente, 200 livros sobre diversos temas, os quais foram muito bem recebidos pela nobreza e pelas pessoas cultas de então.

Entre 1490 e 1520, a inovação de Gutenberg já havia se estabelecido em vários lugares, e o livro científico impresso passa a fazer parte do panorama editorial europeu. Por exemplo, em 1491, em Veneza, publica-se um compêndio de conhecimentos médicos, intitulado Fascículo de Medicina. Era uma coleção de textos universitários na qual se misturavam conhecimentos de Medicina da Antiguidade e da época medieval com inovações da Renascença. Publicado originalmente em latim, segundo a fonte Metropolitan Museum of Art (2010), teve 
edições em outros idiomas, como italiano e espanhol. Impresso em folhas soltas, trazia significativa quantidade de ilustrações, reproduções da anatomia masculina e feminina, com detalhes que possibilitavam a cura de feridas. Graças à nova imprensa, tais informações se tornaram disponíveis a estudantes, aprendizes de cirurgião, barbeiros, sangradores e ao público em geral (TOMÁS, 2005).

Apesar de essas obras pioneiras poderem ser consideradas de divulgação científica, autores, como Calvo Hernando (2006); Massarani e Moreira (2004); e Semir (2002), consideram que, como gênero literário distinto, a produção de obras de divulgação da ciência ocorrera, de fato, apenas a partir dos séculos XVII e XVIII.

A expressão divulgação científica, no entanto, deve ser entendida no contexto de cada época. Ziman (1981) lembra que até a Revolução Científica do século XVII, apenas as reduzidas elites intelectuais tinham acesso aos saberes relacionados com o mundo natural, pois os tratados produzidos eram escritos em latim erudito. Após esse século, com o avanço das línguas vernáculas, começaram a aparecer obras de conteúdo científico destinadas a um público maior. Num mundo onde a influência da religião permeava todas as atividades, os eruditos tentavam se proteger, esforçando-se para obter legitimidade e reconhecimento para a ciência e para sua produção.

Para tornar seus textos acessíveis a um número maior de pessoas, estudiosos e filósofos passaram a escrever em línguas vernáculas, relegando o latim. O êxito editorial de diversas obras na Europa, nos séculos XVI e XVII, indica que uma quantidade grande de leitores passou a ter acesso a elas. Dentre outros, eis exemplos de sucessos editoriais do período: livro de segredos naturais (Secreti) publicado sob o nome de Alessio Piemontese, teve 24 edições em italiano; 28 em francês; 15 em alemão; 14 em inglês; 10 em latim; sete em flamengo; três em espanhol; dois em polonês; e um em dinamarquês. O livro Silva de varia lección, de Pedro Mexia, dentro de um século, ganhou 32 edições em espanhol; 31 em francês; 30 em italiano; cinco em inglês; cinco em flamengo e quatro em alemão. De acordo com Tomás (2005), o movimento de produção e de divulgação dos conhecimentos da época impulsionou o avanço da ciência que iria ocorrer em seguida, no período denominado Revolução Científica: uma ciência baconiana, baseada em evidências, profundamente crítica, apoiada na recuperação de saberes empíricos e aplicados.

A penetração dos livros de Isaac Newton, Princípios matemáticos da Filosofia natural, publicada em 1687, e Óptica, de 1704, influenciaram a pesquisa do mundo físico. A partir da segunda metade do século XVII, a chamada Filosofia experimental - a nova ciência - se consolidou, e paralelamente, emergiram e se estabilizaram as sociedades científicas. A ciência começou a ser vista como conhecimento diferente da Filosofia e de conhecimentos humanísticos. Ocorreu, também, a distinção e a separação entre a divulgação e a educação científica da educação humanística geral (MALET, 2002).

Ainda de acordo com o autor supracitado, os iluministas do século XVII acreditavam no poder do conhecimento para livrar a sociedade da superstição, ignorância e tirania da fase anterior. Os ideais iluministas e a ciência experimental e matematizada que então se desenvolvia inspiraram novas linhas de pensamento moral, estético e político, as quais, por sua vez, estimularam a publicação de várias obras de divulgação. Dentre elas, algumas foram escritas por intelectuais e cientistas de primeira linha, como Bernard le Bouyer de Fontenelle; Voltaire (pseudônimo de François-Marie Arouet); Leonhard Euler; 
Jean Le Rond D'Alembert; Denis Diderot; e Georges-Louis Leclerc, o Conde de Buffon ou Georges Buffon.

No século seguinte, século XVIII, a urbanização crescente provocou mudanças na organização social, fazendo emergir nova classe média que viria a se tornar o público-alvo das iniciativas de divulgação científica. Tanto na França quanto na Inglaterra, o novo grupo social acolheu livros sobre a Filosofia de Newton e freqüentou cursos de introdução à nova Filosofia mecânica e experimental, que divulgavam conhecimentos sobre o desenvolvimento técnico e econômico (MALET, 2002).

\section{Século XVI: as primeiras academias de ciência e a divulgação da ciência}

Burkett (1990) relata que a redação e a divulgação científica derivam de um sistema de comunicação iniciado ainda no século XVI, quando os primeiros cientistas se encontravam às escondidas para evitar a censura da Igreja e do Estado. A tradição da comunicação aberta e oral sobre itens científicos teria brotado dessas reuniões, às quais compareciam cientistas, e, também, nobres, eruditos, artistas e mercadores.

As primeiras academias eram vistas com desconfiança pelos governos dos países onde foram fundadas, e, muitas vezes, sofreram repressão. Na Itália, a primeira academia de ciência foi criada em Nápoles, em 1560, por Giambattista della Porta. Conhecida pela designação de Accademia Secretorum Naturae ou Accademia dei Segreti, teve suas atividades encerradas, em 1580, pela inquisição, sob a alegação de fazer oposição às autoridades eclesiásticas.

Outro episódio que mostra a repressão às academias ocorreu, também, na Itália, na Accademia del Cimento (Academia do Experimento). Instalada em 1657, em Florença, sob a proteção do Duque Ferdinand de Médici e de seu irmão Leopoldo, foi fechada 10 anos mais tarde. O encerramento ocorreu coincidentemente com a indicação de Leopoldo a cardeal, fato que levou os historiadores a suspeitarem de negociação com a Igreja - a indicação de Leopoldo para o cargo de Cardeal pela extinção da Academia, que incomodava a Igreja, até porque, como Bernal (1939) e Burkett (1990) confirmam, diversos filiados foram perseguidos pela inquisição.

$\mathrm{Na}$ Inglaterra, também havia temor de repressão pelo Governo. Para burlar a fiscalização, a Royal Society for the Improvement of Natural Knowledge mudava, com freqüência, a cidade de realização de suas reuniões. Seus integrantes se comunicavam por cartas pessoais, uma vez que este tipo de correspondência não era aberto pelo Governo. Em 1667, o então secretário da Royal..., Henry Oldenburg, foi preso na Torre de Londres pelos comentários que fez, numa comunicação científica, sobre a Guerra da Inglaterra com a Holanda pelo comércio das Índias Orientais, fato que mostra que o temor de repressão tinha fundamento (BERNAL, 1939; BURKETT, 1990).

Apesar da ameaça da repressão, as academias de ciência espalharam-se pela Europa do século XVII. Na Inglaterra, a Royal Society foi proposta por Francis Bacon, em 1620, e aprovada por Charles II, Rei da Inglaterra, em 1622. Seus membros se encontraram durante muitos anos no Gresham College, em Londres, e em Oxford, sob a denominação de invisible college (BURKETT, 1990). De acordo com Ziman (1981), o colégio invisível se constituía mais em comunidade intelectual do que em conjunto de instituições ou de construções materiais. Os elos entre os sócios não se baseavam em normas, obrigações 
legais ou transações financeiras, mas, sim, no intercâmbio de informações e de conhecimentos. Schwartzman (2001) argumenta que o objetivo original da Royal Society era eminentemente prático, experimental e técnico. Seus membros eram inventores e tratavam de "coisas úteis". A busca por uma forma original e inovadora de conhecimento do mundo, incorporada à ciência experimental, motivava o apoio e o estímulo à pesquisa científica.

Em Paris, por volta de 1631, também ocorriam reuniões privadas, no Salão de Etienne Pascal. O grupo foi reconhecido por Louis XIV, em 22 de dezembro de 1666, como Académie des Sciences (BERNAL, 1939; BURKETT, 1990). Para Schwartzman (2001), a Academie... tinha objetivo explícito e altamente prático de permitir a expansão da indústria e do comércio naquele País. Não era uma sociedade de amadores, mas de profissionais, ou seja, 20 pesquisadores apoiados pelo Governo francês para resolver problemas apresentados pelos ministros do Rei. A Académie des Sciences foi instituída como órgão governamental orientada para a prática, em tentativa de salvar a Académie Montmor, onde se reuniam cientistas, como Pierre de Fermat, Blaise Pascal e Pierre Gassendi, correspondentes de Galileu Galilei, René Descartes e Thomas Hobbes, mas que atravessava sérias dificuldades financeiras. Os cientistas persuadiram os governantes a patrociná-la argumentando sobre sua utilidade para o País, recebendo, por fim, seu apoio. Entretanto, as tarefas atribuídas aos componentes se constituíram em projetos, tais como fontes para os palácios ou invenção de jogos para entretenimento da Corte. A entidade foi reativada e expandida depois de 1699 por iniciativa de Jean-Paul Bignon.

Outras nações seguiram criando academias de ciência em seus territórios: na Alemanha, Frederico da Prússia instalou, em Berlim, a Preußische Akademie der Wissenschaften (Academia Prussiana de Ciências), em 1700. No século XIX, 1863, nos EUA, foi a vez da National Academy of Sciences (BERNAL, 1939; BURKETT, 1990).

Os cientistas que iniciaram as academias comunicavam seus resultados por meio de cartas porque, confundidas com a correspondência pessoal e comum entre as pessoas, tais cartas, como antes dito, geralmente, não eram abertas pelo Governo. De acordo com Ziman (1981), tudo que era discutido nas reuniões das primeiras academias era registrado e posteriormente impresso, para servir de fonte de consulta pelos sócios que não puderam comparecer. Tais impressos recebiam o nome de anais ou atas das respectivas sociedades. As cartas enviadas às academias, as Letters, originaram os primeiros periódicos / revistas científicas.

\section{Século XVII: os primeiros periódicos científicos e de divulgação científica}

Há opiniões divergentes sobre qual foi o primeiro periódico realmente científico: Journal de Sçavans, publicado por Denis Sallo, na França, cujo primeiro fascículo apareceu em 5 de janeiro de 1665 ou Philosophical Transactions, editado na Inglaterra, três meses depois, por um grupo de filósofos ingleses, entre os quais Robert Boyle e Henry Oldenburg, este último, então, secretário da Royal Society for the Improvement of Natural Knowledge. A controvérsia tem como origem o fato de a publicação inglesa, apesar de aparecer alguns meses depois da francesa, incluir exclusivamente registros de experimentos conduzidos por membros da Royal Society e correspondência com seus pares europeus, ao 
passo que o Journal de Sçavans publicava também outros temas, como questões legais ou teológicas (HOUGHTON, 1975).

Calvo Hernando (2006) e Semir (2002), com base em outros autores, acreditam ter sido Le Journal des Sçavants a primeira publicação destinada a transmitir conhecimentos científicos para o público leigo. Ziman (1981) acrescenta que o Philosophical Transactions era uma revista científica dirigida à comunidade científica e não ao público leigo. A controvérsia a respeito de qual seria o primeiro título realmente científico ocorre porque a diferença entre público leigo e comunidade científica não parece muito clara na época. Este fato encontra confirmação em Houghton (1975), que lista as funções do periódico científico em meados do século XVIII. Naquele momento, os periódicos tinham se tornado o meio escolhido para comunicação científica, e embora os conhecimentos ainda não estivessem completamente segmentados por especialidades, suas funções já se tornavam claras.

Entre as seis funções citadas por Houghton (1975, p.19, tradução nossa) a primeira é "[...] prover a comunidade científica e os leigos interessados de notícias, em língua vernácula, sobre trabalhos originalmente divulgados em línguas estrangeiras". Houghton (1975) menciona, ainda, um tipo de publicação dedicado ao comércio, técnicos e artesãos, que se tornaria comum no século XVIII. Esse tipo de publicação teria tido como precursor, em 1691, a Collection for the improvement of husbandry and trade (Coleções para o aprimoramento da administração econômica e comércio).

\section{Séculos XVII e XVIII: os livros como instrumentos de divulgação científica}

A obra de Galileu Galilei - Dialoghi sopra i due massimi sistemi del mondo, tolemaico e copernicano (Diálogos sobre os dois sistemas máximos do mundo, ptolomaico e copernicano), publicada em 1632, é considerada por alguns autores importante precursora da divulgação científica. Escrita em italiano, utilizou o diálogo como forma de atrair a atenção de público mais amplo. O diálogo consistia em discussão, ao longo de quatro dias, entre três personagens:

1. Salviati - na realidade, Filippo Salviati (1582-1614), cientista e astrônomo de família nobre de Florença, amigo de Galileu representava as opiniões do amigo, e defendia o sistema copernicano.

2. Sagredo - outro amigo de Galileu, Giovanfrancesco Sagredo (15711620) -representava uma pessoa inteligente, com visão neutra e em busca da verdade. Fazia as perguntas e se deixava convencer por Salviati.

3. Simplicio - filósofo do século XVI que defendeu os fundamentos aristotélicos - representava o defensor da teoria clássica de Ptolomeu e Aristóteles e, em cuja boca Galileu colocou os argumentos do Papa Urbano VII.

De acordo com Sánchez Ron (2002), a lógica que presidiu o diálogo entre os três protagonistas e a habilidade de Galileu em apresentar o sistema heliocêntrico e geocêntrico foram utilizados como instrumento de introdução à essência do que é a ciência, numa estratégia de comunicação científica para leigos. Mas há controvérsias sobre a intenção do livro. Tomás (2005) o apresenta como livro científico, ao tempo em que Semir (2002) o considera predecessor da 
divulgação científica. A publicação, no entanto, foi certamente notada e temida pela Igreja, pois foi ela que deu início ao processo de inquisição contra Galileu. Até aquela época, a atenção do público leitor de livros de ciência, dos censores e dos defensores da ciência tradicional estava voltada para os denominados "livros de segredos naturais", assim designados para deixar claro que se tratava do mundo natural e não do sobrenatural. Isto é, a atenção não se voltava para obras de matemáticos e de astrônomos, inclusive, os Dialoghi passaram a integrar a lista dos livros proibidos da Igreja Católica, permanecendo como tal até 1822.

No século XVII, as atividades de divulgação dos conhecimentos científicos se desenvolveram e se consolidaram. Bernard le Bouyer de Fontenelle é considerado um autor pioneiro da divulgação científica, pela publicação, em 1686, de Entretiens sur la pluralité des mondes (Diálogos sobre a pluralidade dos mundos). Seu livro apresenta os descobrimentos astronômicos dos séculos XVI e XVII, o sistema solar heliocêntrico, que coexiste com outros sistemas e mundos, possivelmente também habitados. A obra alcançou êxito sem precedentes, que se prolongou durante quase todo o século XVIII, com 33 edições somente entre 1686 e 1757, sem contar as traduções (MALET, 2002; SEMIR, 2002).

Fontenelle utilizou a mesma estratégia de Galileu - o diálogo. Os protagonistas são o autor e uma marquesa - anônima - que conversam no jardim de sua residência de campo enquanto observam o céu estrelado. O conteúdo científico é claro e inteligível graças ao diálogo repleto de elegância e inteligência. A marquesa, que faz contraponto ao autor, representa o papel das mulheres educadas da alta sociedade parisiense, que freqüentavam os salões, locais semipúblicos, onde aconteciam os debates intelectuais.

Malet (2002) comenta, ainda, que Fontenelle usava metáforas com habilidade, facilitando o entendimento de fenômenos científicos. Por exemplo: comparou a natureza a um teatro de ópera, no qual os espectadores percebem o movimento dos cenários, mas não sabem o que os faz se moverem, porque não vêem o que acontece por trás dos bastidores, onde os movimentos são provocados com auxílio de cabos e de outros equipamentos. Desta forma, a visão dos espectadores é relativa, em relação ao local onde se encontram, aos movimentos dos cenários e aos instrumentos que utilizam para observá-los.

As atividades de Fontenelle como divulgador fizeram com que fosse indicado para ser secretário permanente da Académie des Sciences, em 1699. Entre suas funções, estava a responsabilidade de redigir as atas da sociedade e ser seu porta-voz, transformando as comunicações sobre ciência produzida pelos acadêmicos em algo compreensível para a sociedade culta da época e para os servidores públicos da monarquia, responsáveis pelo financiamento das atividades da Academie... e pelo pagamento dos salários dos acadêmicos (MALET, 2002).

No século XVIII, a ciência se tornou fonte de interesse e de diversão para a aristocracia e para a classe média da Europa, estimulada por livros contendo explicações sobre a Física de Newton, a eletricidade e a história natural. Diversos divulgadores científicos se destacaram, entre os quais a marquesa Émilie du Châtelet (1707-1749). Como possuidora de conhecimento profundo de Matemática, traduziu para o francês a obra de Newton, Princípios da Matemática, escrita originalmente em latim e considerada de alto nível de complexidade e, portanto, inacessível à maioria das pessoas da época. Publicou ainda, em 1740, o livro de divulgação da Física de Newton, Institutions de physique, na forma de lições redigidas para educar os filhos. 
Por sua vez, Voltaire (1694-1778), assim como Émilie du Châtelet, trabalhou para decodificar e difundir a obra de Newton, tendo publicado Eléments de la philosophie de Newton. Leonhard Euler, outro autor da época, publicou, entre 1768 e 1772, as Lettres a une princesse d'Allemagne sur divers sujets de physique et de philosophie (Cartas a uma princesa alemã sobre diversos temas de Física e Filosofia). Composta de três volumes, foi inspirada em aulas ministradas a uma princesa da Casa Real da Prússia. Seu sucesso foi grande, com tradução para italiano, espanhol, dinamarquês, holandês, sueco, russo, alemão, inglês e francês (MALET, 2002; MASSARANI; MOREIRA, 2004).

Para Malet (2002), o texto que melhor exemplifica a função da divulgação científica, do progresso técnico e material, da Psicologia, da ética e da crítica social, naquele momento histórico, foi a Enciclopédie de D'Alembert e Diderot, produzida entre 1751-1765. Em sua opinião e com a concordância de Semir (2002), foi para responder à necessidade do público em conhecer as maravilhas da ciência e da técnica que Diderot, por solicitação do editor Le Breton, a concebeu. Vale lembrar que o iluminismo do século XVIII utilizou a ciência como poderoso instrumento político para atacar concepções conservadoras e absolutistas sobre o poder político que se apoiavam em concepções religiosas dogmáticas da teologia católica. E, assim, a difusão da obra de Newton e a edição da Enciclopédie tiveram papel essencial nesse aspecto.

\section{Século XVIII: as conferências científicas}

Ainda no século XVIII, ocorreram as primeiras conferências científicas públicas não universitárias. Possuíam o formato de cursos curtos ou de aulas magnas, ou mais extensas, se prolongando por vários meses. A moda das conferências públicas sobre Filosofia experimental tomou conta da Europa, começando pela Inglaterra e Holanda, seguindo por França e Itália, atendendo, predominantemente, à população urbana. Aulas ou cursos eram ministrados por membros das academias e / ou das sociedades científicas, alguns deles, nomes importantes, como Jean-Antoine Nollet e o conde de Buffon, ou por outros professores fora das academias, como artesãos fabricantes de instrumentos científicos, engenheiros e outros profissionais. Os cursos ocorriam na Corte, em palácios, cafés e bares ou nas casas dos próprios mestres (MALET, 2002).

Nas conferências, instrumentos científicos, tais como microscópios e telescópios, desempenhavam papel central, facilitando a demonstração das maravilhas da natureza. Outros aparelhos, especialmente produzidos, eram usados para gerar efeitos espetaculares, a exemplo de efeitos magnéticos e óticos, e pesos que se equilibravam de forma inesperada. Eram recursos para ilustrar as teorias e possibilitar aos participantes visualização do que somente seria possível via experimentação. As conferências possuíam, portanto, componente lúdico e de entretenimento, com o objetivo de captar e reter a atenção do público (MALET, 2002).

Ziman (1981) refere-se às conferências científicas populares, patrocinadas pela Royal Institution of Great Britain, entidade fundada, em Londres, ano 1799, por Benjamin Thompson, Conde de Rumford. Tratava-se de um tipo de colégio técnico, em que a ciência socialmente relevante era apresentada ao povo por meio de conferências populares que incluíam séries infantis. 


\section{Século XIX: contexto científico e publicações}

Ao final do século XVIII e início do século XIX, as disciplinas científicas começaram a se emancipar das disciplinas mais gerais, até se configurarem como autônomas. Os filósofos naturais deixaram de se ocupar com aspectos diferenciados do mundo natural, passando a se dedicar unicamente a uma especialidade científica (PANZA; PRESAS, 2002). O século XIX foi considerado o século da ciência, da educação e das transformações políticas, econômicas e sociais, produzindo condições que propiciam atividades de divulgação científica.

A capacidade de ler e escrever da população aumentou em quase todos as nações européias, em especial, nas áreas urbanas e, principalmente, na Inglaterra e na Alemanha. $O$ avanço de novas técnicas de impressão e a superação do analfabetismo criaram condições propícias para a divulgação da ciência, firmando-a como força cultural influente em todos os setores da sociedade e, por excelência, como motor do progresso. Temas de interesse da sociedade eram discutidos sob uma ótica científica, num ambiente em que a religião, até então, tinha tido a última palavra. Idéias antes aceitas sem discussão começaram a ser questionadas. Outra característica da época, a paixão pela informação, cujas raízes estão no século XVIII, motivou a coleta de objetos de várias partes do mundo, então catalogados e exibidos em museus e exposições. Também foram coletadas informações estatísticas e realizados estudos com microscópios e com instrumentos de medida (BURKE, 2003).

Massarani e Moreira (2004) relatam que, no século XIX, prevalecia o otimismo quanto aos benefícios do avanço científico e técnico, exposto em grandes exposições universais e nacionais, que também ocorreram no Brasil. Dirigidas à população em geral, mantinham como característica fundamental a idéia de aplicação da ciência à indústria. Nos EUA, as exposições contaram com a participação de reconhecidos cientistas que se dedicaram à difusão do conhecimento científico na expectativa de contribuir para o progresso da economia industrial emergente. Nos países dependentes, registrou-se um movimento em direção à divulgação do conhecimento científico em língua local, envolvendo a tradução de textos estrangeiros e a edição de revistas regionais na língua local, como foi o caso específico da Índia.

Para Semir (2002), em meados do século XIX, o livro científico contribuiu para a industrialização das atividades editoriais, desempenhando papel fundamental na criação de grandes conglomerados comerciais, à semelhança dos grupos Hachette e Larousse (França) e McMillan, Inglaterra. O fenômeno se generalizou pela Europa, dando lugar ao surgimento de novas publicações periódicas tanto técnico-científicas quanto de divulgação.

Dentre os autores de livros de divulgação científica, Camille Flammarion destacou-se na França, por suas propostas inovadoras. Para ele, divulgação científica não consistia somente na exposição dos principais resultados científicos, mas deveria despertar a paixão pela ciência. No caso de seus livros, era a astronomia. Achava necessário distinguir o aspecto descritivo do aspecto técnico e não confundir as pessoas com a mitologia fantástica destituída de base científica e experimental. $O$ trabalho de divulgação nem poderia se eximir de rigorosas observações do céu nem renunciar aos instrumentos técnicos necessários ao rigor intelectual e à disciplina científica (PANZA; PRESAS, 2002). Flammarion publicou, em 1880, o livro Astronomie populaire (Astronomia popular), cuja venda excedeu 100.000 exemplares da primeira edição e em 1862, La 
pluralité des mondes habités ( $A$ pluralidade dos mundos habitados), dentre diversos outros trabalhos (SEMIR, 2002).

A partir do século XIX, o termo ciência e expressões relacionadas com a ciência deixaram de ser de uso restrito aos círculos eruditos, e se incorporam à cultura cotidiana. Isto pode ser visto como resultado de esforços de divulgação das modernas idéias científicas para a população sem formação científica (PANZA; PRESAS 2002).

Semir (2002), citando Bernadette Bensaude-Vincent, professora de História e Filosofia da Ciência, Université Paris $X$, afirma que o estabelecimento definitivo de atividades de divulgação científica, em todas as suas formas, como gênero destinado ao público de massa, se deu na segunda metade do século XIX. O período entre 1870 e 1900 pode ser considerado como a "idade de ouro" da divulgação científica, quando o desejo de mostrar coincidiu com o desejo de saber.

A separação entre a comunicação da ciência entre cientistas e a comunicação visando à sua popularização ocorreu na década de 1880 , quando a atividade de pesquisador científico se tornou ocupação de tempo integral, deixando de fora os comerciantes, clérigos e outros que a praticavam como meros amadores. A distinção social entre ciência e público começou com a formação das comunidades científicas e com a institucionalização da ciência como atividade, com regras e praticantes distintos de outros ofícios (BURKETT, 1990; MASSARANI; MOREIRA, 2004).

\section{Século XIX: A criação das associações para o progresso da ciência}

Outro acontecimento de destaque do início do século XIX foi a criação das associações para o progresso da ciência. Delas participavam tanto acadêmicos e cientistas profissionais quanto leigos, e competiam às associações desenvolver ações de divulgação científica voltadas à sociedade em geral, por meio da imprensa. Com o objetivo de aliar ciência e sociedade, essas entidades promoviam reuniões anuais em cidades mais distantes, com a apresentação de palestras e conferências sobre temas variados. No entanto, com o decorrer dos anos, as conferências passaram a ser dominadas por cientistas que expunham suas descobertas, de modo a transformá-las em mais um canal de comunicação entre os integrantes da comunidade científica. A British Association, fundada em 1831, foi a primeira dessas sociedades, mas, segundo Ziman (1981), só alcançou o auge do poder e do prestígio na segunda metade do século XX.

$\mathrm{Na}$ mesma época, pesquisadores de áreas específicas fundaram seus próprios grupos profissionais assumindo o controle das organizações nacionais da área, tais como American Chemical Society (ACS) e American Association for the Advancement of Science (AAAS), entre outros, abandonando as sociedades locais.

\section{Século XIX: periódicos e revistas - Nature e Science}

No século XIX, surgem periódicos científicos nacionais no estrito e novo sentido da ciência. Por exemplo, na Inglaterra, em 1869, o astrônomo Norman Lockyer e o editor McMillan fundaram Nature, que se tornaria uma das revistas mais importantes do mundo (SEMIR, 2002). Durante esse século, apareceram e desapareceram diversos títulos, como American Journal of Science, 1818; 
Scientific American, 1845; American Naturalist, 1860; e Science News, de 1878. Mas, apesar de tantas novas revistas, os cientistas reclamavam que as notícias sobre ciência eram fragmentadas e não respeitavam as linhas disciplinares rigidamente traçadas.

Ainda no século XIX, em 3 de julho de 1880, Thomas A. Edison e John Michels deram início à edição de Science, que até hoje mantém prestígio. Porém, este título passou por várias mãos e diferentes situações até adquirir estabilidade. No início, num flagrante período de profissionalização da ciência, em consonância com o pensamento de Burkett (1990), o comportamento amador de Michels e o controle de gastos financeiros por parte de Edison mantiveram afastados colaboradores ilustres. Mais tarde, o título mudou de proprietário e de foco, adotando orientação acadêmica e profissional. Em 1883, se tornou propriedade de Alexander Graham Bell e de seu sogro Gardiner Hubbard, dono, também, da National Geographic Magazine, publicação de caráter popular. Mais adiante, em 1894, Science é interrompida, por falta de recursos financeiros.

Os líderes da AAAS haviam decidido adquirir Science, porém, o psicólogo James Mckeen Cattell, pesquisador e professor da Columbia University, se adiantou e se tornou editor, conseguindo que os antigos proprietários the concedessem a propriedade da revista. Cattell a editou por 50 anos. Depois de sua morte, Science foi vendida para AAAS por 250 mil dólares (BURKETT, 1990).

\section{Livros infantis}

Os livros infantis também foram adotados para divulgar conhecimentos científicos. Malet (2002) comenta que, ao final do século XVII, a literatura infantil surgiu na Europa, a fim de atender ao público com idade entre três e 15 ou 16 anos. Suas características são páginas pequenas, margens grandes, letras grandes e simplificadas, inserção de ilustrações, estrutura gramatical e vocabulário simplificados.

No entanto, o grande impulso na produção de livros infantis se deu a partir do século XVIII, com o editor inglês John Newberry (1713-1767) que se dedicou à sua edição, desde 1740, com muito sucesso. Entre suas publicações, destaca-se a série Tom Telescope, cujos temas eram inspirados no saber científico da época, e apresentados como lições dadas pelo "autor" Tom Telescope, provavelmente, ainda segundo Malet (2002), pseudônimo de Newberry.

A série ganhou sete edições, entre 1761 e 1787 . O livro mais famoso foi The Newtonian system of philosophy adapted to the capacities of young gentlemen and ladies, and familiarized and made entertaining by objects with which they are intimately acquainted, hoje, disponível no Google Books, e que, à época, obteve retumbante êxito de vendas, com a estimativa de 25.000 a 30.000 exemplares. Constituiu-se num dos livros mais interessantes daquele momento histórico, escrito para jovens entre 12 e 15 anos. São seis capítulos, distribuídos em 136 páginas, contendo muita informação, porém com linguagem clara, desenhos e figuras. O primeiro capítulo é sobre matéria e movimento; o segundo, sobre o universo, especificamente, o sistema solar; o terceiro, atmosfera e fenômenos meteorológicos; o quarto, montanhas, vulcões, terremotos, rios e oceanos; o quinto, vegetais e animais; e o último, sobre o homem, sua maneira de compreender o mundo, a dor e a felicidade. O livro faz referência a Deus como inteligência divina responsável pela ordenação do universo de conformidade com um plano. Critica a crueldade e a maldade no trato com os animais, bem como a 
indiferença em relação à dor, além de contemplar e crueldade humana em relação ao tráfico e ao trabalho escravo (MALET, 2002).

Ainda para esse autor, em 1750, foi publicado o livro anônimo $A$ museum for young gentlemen and ladies (também no Google Books), com 189 páginas e considerado a primeira enciclopédia infantil. Compreendia a história da GrãBretanha, o sistema solar como conhecido à época e as diferentes nações do mundo com seus costumes e hábitos, a erupção do Vesúvio, as sete maravilhas do mundo, dentre outros temas, e todos com ilustrações. A publicação teve tal êxito, que foi editada durante os 40 anos seguintes.

Outro autor de destaque na literatura infantil foi Samuel Ward, que publicou, em 1775 e 1796, A modern system of natural history (no Google Books), em 12 volumes, voltados para crianças. Malet (2002) afirma que, na Inglaterra do século XIX, o número de publicações com conteúdo científico direcionadas ao público infantil não seria inferior a 30 títulos. A literatura infanto-juvenil, por se dirigir a mentes em formação, foi utilizada como via para difundir as idéias do iluminismo na sociedade e gerar novas atitudes sociais.

Outra estratégia de divulgação científica direcionada ao público infantil foram os jogos científicos, utilizados a partir de 1750. Eram jogos de mesa baseados no conhecimento de nomes e de dados, e incluíam modelos de instrumentos e de máquinas, microscópios e telescópios para uso familiar, bem como, modelos em miniatura de zoológicos e aviários. Entre 1790 e 1830, de acordo com Malet (2002), o jogo Pleasures of Astronomy, conhecido como Science in Sport, elaborado por John Wallis e publicado em 1804, gozou de muita popularidade.

\section{Jornalismo científico}

Com o avanço do jornalismo e de sua influência na sociedade, a informação científica passou a ser incluída nos jornais. Primeiramente, por meio dos cientistas, ansiosos em divulgar seus trabalhos; posteriormente, pelos próprios jornalistas. Segundo Calvo Hernando (2006), a primeira informação científica na imprensa foi uma notícia de dois parágrafos sobre a epidemia de febre amarela nas colônias britânicas, publicada em Boston, em 1690, no também considerado primeiro jornal norte-americano - Publick occurrences both foreign and domestick. Este, porém, foi editado uma única vez. As autoridades o consideraram perigoso e ordenaram seu fechamento.

Semir (2002), com base em Bienvenido Leon (Universidade de Navarra), e Calvo Hernando (2006) afirmam que o primeiro jornal a incluir artigos científicos foi Gazzette de France, fundado, em 1631, por Teofrasto Renaudot. Embora não fosse publicação exclusivamente científica, apresentava o resultado de reuniões científicas semanais. Note-se que este jornal antecede os primeiros periódicos considerados científicos, os citados Journal de Sçavans e Philosophical Transactions, ambos de 1665.

Um fato considerado significativo para o jornalismo científico foi a abertura, em 1837, das sessões e das atas da Académie des Sciences para os jornalistas, patrocinada pelo astrônomo François Jean Dominique Arago. A iniciativa de François Arago provocou polêmica entre os acadêmicos. Alegavam que "[...] o mundo da ciência poderia perder sua credibilidade se jornalistas fossem admitidos na sala [de sessões], pois sua pena indiscreta poderia revelar impunemente erros que os sábios pudessem proferir em um momento de distração" (SEMIR, 2002, 
tradução nossa). Apesar disto, prevaleceram os defensores da transparência científica, movimento que coincidiu com o incremento do número de jornais, graças aos avanços tecnológicos que então permitiram agilizar e baratear a produção.

Como Massarani e Moreira (2004) afirmam, nos EUA, a profissionalização do jornalismo científico, já no século XX, é marcada pela criação da Science Server, agência de notícias científicas produzidas por e para jornalistas científicos. Os cientistas norte-americanos, ao contrário do que ocorria nas sociedades científicas da Europa, não se envolviam em assuntos políticos, declarando-se e ao seu trabalho acima da política. E, para Burkett (1990), o jornalismo norte-americano também seguiu o caminho "neutro", caracterizado pela objetividade.

Na América Latina, de acordo com Massarani e Moreira (2004), foram os próprios cientistas que se envolveram no processo de comunicação científica desde o século XIX. Pretendiam incrementar sua presença na sociedade para reafirmar sua legitimidade profissional, intensificar a comunicação com os pares e com outros grupos sociais, em busca de fortalecer alianças com as instituições que detinham poder.

\section{Museus e centros de ciência}

De acordo com Gaspar (1993) e Valente e Cazelli e Alves (2005), em conseqüência do maior interesse pela cultura e pela ciência nos séculos XVII e XVIII, começaram a surgir os primeiros museus públicos. Filósofos e cientistas de então, entre os quais Bacon, Descartes e Gottfried Wilhelm Von Leibniz (Wilhelm Leibiniz), antes já enfatizavam a importância dos museus dedicados à ciência, mas com funções educacionais. Por exemplo, Leibiniz defendia a criação de um "[...] museu voltado para esclarecer e entreter o público", onde seriam feitas "[...] demonstrações experimentais com água, ar e vácuo", realizados testes com vários tipos de máquinas, e o telescópio seria usado para mostrar a lua e outros astros celestes, além de exibir "[...] plantas raras e painéis sobre anatomia humana" (DANILOV, apud GASPAR, 1993, p. 10).

A literatura aponta o Museu Ashmoleano, aberto em 1683, como o primeiro museu público de ciência, doação de Elias Ashmole à Oxford University, e a quem sua denominação homenageia. A doação consistia de coleção de curiosidades de todos os tipos, que servia, prioritariamente, como material de pesquisa para os alunos daquela Universidade. Mas o primeiro museu público de âmbito nacional britânico foi o British Museum, fundado quase 80 anos mais tarde, em 1753, e aberto ao público em 1759. Também foi formado com base em coleção particular, no caso, de Sir Hans Sloane, físico e naturalista. Sua coleção consistia, sobretudo, de livros, manuscritos, espécimes naturais, moedas e medalhas, gravuras e desenhos, além de material etnográfico. Segundo o site oficial do British Museum (2010, tradução nossa), "[...] desde seu início, concede entrada franca a todos os estudantes e pessoas curiosas"

A criação de museus no século XVIII não se restringiu à Inglaterra. $\mathrm{Na}$ França, em 1794, a Assembléia Nacional Francesa aprovou a criação, em Paris, do Conservatoire National des Arts et Métiers, pioneiro de um tipo de museu consagrado ao ensino de ciência e de artes aplicadas. A característica predominante desses museus é a exibição de artefatos relevantes da história da ciência e da técnica, como máquinas, invenções, modelos, ferramentas, projetos, 
descrições, livros de artes aplicadas, utensílios de caráter industrial e profissional. No século XX, o Conservatoire... transformou-se no Musée National des Techniques, voltado à aprendizagem de técnicas e de ofícios e à promoção do desenvolvimento industrial (GASPAR, 1993; VALENTE; CAZELLI; ALVES, 2005).

Wittlin (apud GASPAR, 1993) considera que, apesar de vários outros museus com características idênticas terem surgidos no século XVIII, seu sucesso não foi grande em termos de divulgação científica e de atração pública. O insucesso parece advir da desorganização das coleções, do despreparo dos organizadores e da imponência das edificações, que intimidava os visitantes. Mas tal situação se alterou no século XIX, com a crescente experiência de curadores, pesquisadores e museólogos. Para Gaspar (1993), novos museus foram então instituídos, aproveitando coleções e edificações de exposições e feiras industriais, comuns naquele período. É o caso, por exemplo, da Great Exhibition of the Works of Industry of all Nations (Exposição da Indústria de Todas as Nações), realizada em Londres, em 1851, e que deu origem, em 1857, ao South Kensington Museum of Industrial Arts, renomeado Science Museum, em 1909, quando se dá a separação dos acervos de artes e decoração:

[...] Surgiram os museus históricos ou nacionais, estimulados pela ascensão do nacionalismo e os museus etnológicos, fruto da expansão colonial. A Revolução Industrial e o progresso científico deram origem aos museus de ciências e tecnologia, enquanto que o impacto da teoria de Darwin influiu fortemente na proliferação de museus de história natural por todo o mundo [...] (GASPAR, 1993, p. 11).

A função educativa dos museus foi se firmando na Europa, no início do século XX. Um dos pioneiros foi o Deutsches Museum, situado em Munique, fundado em 1906. Introduziu inovações com a intenção de tornar as conquistas da ciência e tecnologia ( $C \& T$ ) compreensíveis ao público e também de mostrar à sociedade a relevância do trabalho de engenheiros e cientistas. Recorria a réplicas de animais e equipamentos em tamanho natural, e expunha modelos que podiam ser acionados pelo visitante, de forma a ilustrar o funcionamento de fenômenos reais e dos princípios da Física (GASPAR, 1993; UCKO, 1985; VALENTE; CAZELLI; ALVES, 2005).

As novidades introduzidas pelo Deutsches Museum inspiraram a criação, em 1933, do Museum of Science and Industry, Chicago, EUA. Julius Rosenwald, empresário e filantropo, se empenhou pessoalmente na iniciativa, motivado pelo entusiasmo que o Deutsches... despertara em seu filho de oito anos: ao "[...] pressionar botões ou alavancas podia fazer todo tipo de coisas excitantes" (ALEXANDER; ALEXANDER, 2008, p. 96, tradução nossa). De fato, o Museum of Science and Industry marcou o início de intenso movimento de criação de museus em C\&T nos EUA. O estilo lúdico de apresentar as coleções consolidou-se nas décadas de 60 a 80 do século XX, influenciando a fundação, em Paris, do Palais de la Découverte, e em Londres, a reorganização do Science Museum (GASPAR, 1993; VALENTE; CAZELLI; ALVES, 2005).

Nos EUA, surgiram os chamados centros de ciência (science centers), um tipo de museu de ciência com característica multidisciplinar, integrando ciência, tecnologia e arte e incorporando técnicas interativas de caráter experimental. São espaços que seduzem, provocam, atraem e motivam o visitante a entrar em contato com fundamentos da C\&T, graças a experimentos do tipo "faça você mesmo" (VALENTE; CAZELLI; ALVES 2005). 
Em meados do século XX, após as duas Grandes Guerras, as ações de divulgação científica se intensificaram e aperfeiçoaram sua qualidade. Novos meios de divulgação foram explorados, como as novas tecnologias audiovisuais, em especial, rádio e cinema, o que permitiu atingir públicos mais abrangentes. Por meio desses canais, grandes nomes da ciência da época tornaram-se figuras familiares, como os ganhadores de Prêmio Nobel, Albert Einstein e Marie Skłodowska Curie (ou Marie Curie). Massarani e Moreira (2004) acreditam que os próprios cientistas começaram a perceber o valor da educação e da divulgação da ciência, o que faz com que Valente e Cazelli e Alves (2005) caracterizem o período imediatamente posterior às Grandes Guerras como a "idade da ciência". Nessa fase histórica, com o estímulo advindo das necessidades da guerra, muito esforço foi desprendido em direção às conquistas científicas do século XIX, atingindo patamares sem precedentes na história da ciência. A percepção pública e governamental de que a educação científica é importante para as nações, ganha espaço, especialmente nos EUA, conduzindo à criação de mais centros e museus de ciência.

\section{A divulgação científica na era da tecnologia}

A tecnologia da comunicação, cujo início ocorreu ainda ao final do século XIX, e que se expandiu na metade do século XX, revolucionou a forma de fazer divulgação científica. Rádio, televisão, cinema e imprensa mais apurada, conjugados com o incremento da educação básica, fizeram do século XX a era da informação. Porém, nenhum invento teve o impacto da internet, onde todas as formas de comunicação se fundem, e a informação científica se torna accessível de maneira impensada até então. No espaço virtual, há museus, livros, revistas, enciclopédias, cursos, filmes, sites oficiais, comerciais e pessoais e inúmeras novas formas de comunicar, de acesso gratuito ou pago. É um novo mundo em permanente evolução que ocorre em velocidade crescente, de forma mais abrangente e mais complexa em termos de tecnologia, porém mais simples em termos de acesso para o cidadão. Neste cenário que se convencionou chamar globalizado, as barreiras mais difíceis de derrubar continuam sendo não as tecnológicas, mas as geradas pelas pessoas, pela ambição de ditadores e / ou por preconceitos de crenças.

\section{COMENTÁRIOS FINAIS}

Como visto, relatam-se, aqui, acontecimentos marcantes da evolução de uma idéia nascida e desenvolvida na Europa, mas que se espalha pelo mundo. Trata-se de levar à sociedade os conhecimentos produzidos por cientistas, não na linguagem hermética que caracteriza as comunicações entre eles, mas de forma compreensível que, ao longo do tempo, vem se tornando, cada vez mais, agradável e divertida. O direito à informação científica, hoje, considerado pelos governos democráticos como obrigação, foi sendo conquistado aos poucos, desde o século $X V$, por conta do esforço e da imaginação de homens notáveis de seu tempo, cientistas e não cientistas. No início, a coletividade para quem as informações se destinavam consistia em pequeno grupo de privilegiados que sabiam ler.

À medida que os anos transcorrem e que o conhecimento científico avança e a imprensa se expande pela Europa, novas conquistas sociais são efetivadas, 
e, por conseguinte, mais pessoas têm acesso ao saber, fenômeno que reflete, também, a evolução econômica. A consolidação da profissão de cientista e a conseqüente especialização que ocorre ao final do século XIX marcam, com nitidez, a separação entre comunicação do conhecimento científico entre cientistas e para a sociedade. As iniciativas de divulgação científica crescem em número e diversidade, tornando-se cada vez mais elaboradas. O que temos, hoje, em pleno século XXI, é o resultado do esforço daqueles que, ao longo do tempo, acreditaram no poder do conhecimento e na premência de torná-lo acessível a grupos sempre maiores, em todo o mundo. Olhando para trás, sente-se esperança de que as barreiras ainda existentes também sejam derrubadas e novas formas de acesso surjam.

\section{REFERÊNCIAS}

ALEXANDER, E. P.; ALEXANDER, M. Museums in motion: an introduction to the history and functions of museums. 2. ed. Lanham, UK: Altamira Press, 2008.

BERNAL, J. D. The social function of science. London: Routledge, 1939.

BRITISH MUSEUM. History of the British Museum. Trustees of the British Museum. Disponível em: $<$ http://www.britishmuseum.org/the_museum/history/general_ _history. aspx>. Acesso em: 9 ago. 2010.

BURKE, P. Uma história social do conhecimento: de Gutenberg a Diderot. Rio de Janeiro: Zahar, 2003.

BURKETT, W. Jornalismo científico: como escrever sobre ciência, medicina e alta tecnologia para os meios de comunicação. Rio de Janeiro: Forense Universitária, 1990.

CALVO HERNANDO, M. Conceptos sobre difusión, divulgación, periodismo y comunicación. 2006. 3 p. Disponível em: <http://www.manuelcalvohernando.es/ articulo.php?id=8>. Acesso em: 10 set. 2010.

GASPAR, A. Museus e centros de ciências: conceituação e proposta de um referencial teórico. 1993, 118 f. Tese (Doutorado em Didática) - Faculdade de Educação, Universidade de São Paulo, São Paulo. 1993.

HOUGHTON, B. Scientific periodicals: their historical development, characteristics and control. Connecticut: Linnet Books \& Clive Bingley, 1975.

MALET, A. Divulgación y popularización científica en el sigo XVIII: entre la apología cristiana e la propaganda ilustrada. Quark, Barcelona, n. 26, p. 13-23, oct. / dic. 2002.

MASSARANI, L.; MOREIRA, I. de C. Divulgación de la ciência: perspectivas históricas y dilemas permanentes. Quark, Barcelona, n. 32, abr. / jun. 2004. 
METROPOLITAN MUSEUM OF ART, New York. Johannes de Ketham: fasciculo di medicina (38.52). Heilbrunn Timeline of Art History, 2010. Disponível em: < http:// www. metmuseum.org/toah/works-of-art/38.52>. Acesso em: 1 set. 2010.

PANZA, M.; PRESAS, A. La divulgación de la ciencia en el siglo XIX: la obra de Flammarion. Quark, Barcelona, n. 26, oct. / dic. 2002.

SÁNCHEZ RON, J. M. Historia de la ciencia y divulgación. Quark, Barcelona, n. 26, oct. / dic. 2002.

SCHWARZTMAN, S. Um espaço para a ciência: a formação da comunidade científica no Brasil. Brasília, DF: MCT, Centro de Estudos Estratégicos, 2001.

SEMIR, V. de. Aproximación a la historia de la divulgación científica. Quark, Barcelona, n. 26, oct. / dic. 2002.

TOMÁS, J. P. De los libros de secretos a los manuales de la salud: cuatro siglos de popularización de la ciencia. Quark, Barcelona, n. 37 / 38, sep. 2005 / abr. 2006.

UCKO, D. A. Science literacy and science museum exhibits. Curator, Barcelona, v. 28, n. 4 , p. 287-300, 1985.

VALENTE, M.E.; CAZELLI, S.; ALVES, F. Museus, ciência e educação: novos desafios. História, Ciências e Saúde, Rio de janeiro, v. 12, p. 183-205, 2005. Suplemento,

ZIMAN, J. A força do conhecimento. Belo Horizonte: Itatiaia, 1981.

Title

Scientific communication to non scientists: brief history.

Abstract

The effort to make scientific knowledge accessible to the public in general parallels, in its origin and development, the history of science itself and that of the press. In The text, focus the main facts that marked the trajectory of scientific dissemination in Europe to the public at large, from the XV century to the XX century, stressing events that happened before the inception of the newer communication technologies, which are only brief mentioned. Brief references are also made to efforts registered in the XX Century United States, especially on museums. The text is organized in chronological order, century after century, with the exception but for three topics, scientific journalism, children's books and museums, which are treated separately. Topics within each century include the emergence of the scientific academies and of the scientific periodical, which at first was not aimed exclusively at scientists, the book as instrument of learning, scientific conferences, scientific journalism, children's books, museums.

\section{Keywords}

Communication of science. Scientific communication. Scientific divulgation. Scientific divulgation - historic overview. History of science. 


\section{Título}

La comunicación científica para el público no científico: historia breve

\section{Resumen}

Se relatan los acontecimientos más significativos de la historia y evolución de la divulgación científica para los no científicos, ocurridos en Europa entre los siglos XV y $X X$, con breve referencia a las iniciativas en los Estados Unidos de América, en épocas más recientes. Los datos fueron buscados en estudios publicados, destacando los acontecimientos hasta la introducción de las nuevas tecnologías de información y comunicación, los cuales son someramente mencionados. El orden de exposición es cronológico, siglo tras siglo, pero se hace una excepción en tres temas - el periodismo científico, libros infantiles y museos - al tratarlos en secciones independientes. La narración comienza en el siglo XV, destacando los primeros pasos que se producen junto con el desarrollo de la ciencia y la imprenta. Así, en cada siglo, se analizan: las nuevas academias de ciencia que se extendieron por el continente europeo, cuyas actas dan lugar a las primeras revistas científicas (siglo XVI), el uso del libro como herramienta para la comunicación científica (siglos XVII y XVIII), las conferencias científicas como medio de difusión del conocimiento científico (siglo XVIII), la consolidación y especialización de las disciplinas y conocimientos y, simultáneamente, las revistas científicas desligadas de los vehículos de divulgación científica.

\section{Palabras clave}

Comunicación de la ciencia. Comunicación científica. Divulgación científica. Divulgación científica - evolución histórica. Historia de la ciencia.

Recebido em: 30/08/2010

Aceito em: $28 / 11 / 2010$ 